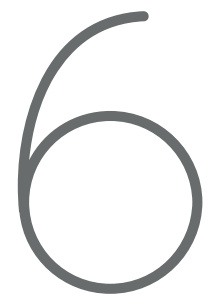

\title{
HERNÁN MALO, CABALlERO DE LA RAZÓN
}

\author{
Jaime Durán Barba
}




\section{Un pensador y su tiempo.}

Aparece en el mundo universitario la figura de Hernán Malo, cuando a su vuelta de estudios universitarios en Europa asume el Decanato de la Facultad de Filosofía San Gregorio, en la segunda mitad de la década de 1960.

Era la época en que América Latina conmovida por el impacto de la Revolución Cubana buscaba dificultosamente nuevos caminos que le permitieran superar la dependencia externa y la injusticia social interna que por desgracia siguen siendo características propias de nuestras sociedades. Movimientos guerrilleros esparcidos por todo el Continente eran la expresión más dramática y violenta de esa angustia por construir nuevos mundos.

En el país, después de los gobiernos de Velasco y Carlos Julio Arosemena, la Junta Militar de Gobierno había implementado un proyecto, mezcla de furia anticomunista y ansias reformistas, que finalmente la enfrentaron a los sectores más conservadores del país que, a la postre, decidieron tomar control directo de la situación a través de Clemente Yerovi y Otto Arosemena Gómez.

A estos gobiernos provisionales sucedía en 1968 el último Velasquismo que, en lo que atañe a nuestro tema, lanzó una feroz ofensiva en contra de las universidades ecuatorianas, conmovidas hasta sus bases por la segunda reforma universitaria.

El mismo golpe dictatorial de Velasco invocó en 1970 como su razón de ser, el combate en contra de la Universidad convertida en lo que Malo llama "Institución perversa", buscando imponer una infame ley de educación superior que mereció el rechazo unánime de los hombres dedicados al estudio y al cultivo de las artes y las ciencias.

Por otra parte, la Iglesia Católica vivía momentos de aguda crisis y por tanto de grandeza. Bajo la conducción de Juan XXIII la Iglesia había comprendido que se encontraba ante un dilema: renovarse o desaparecer. Seguir confundida con los intereses de los poderosos o buscar la renovación volviendo a sus raíces de compromiso con los pobres. Acompañar en su crepúsculo a las fuerzas que habían detentado el poder y que se negaban a toda innovación o buscar resurgir en un nuevo amanecer de una humanidad que buscaba nuevas formas de organización 
social, en la que desaparezca la muerte, la miseria y la injusticia, la explotación del hombre por el hombre. El impacto del Concilio Vaticano II se traducía en nuestra América Latina en el incesante trabajo de los cristianos que buscaban concretar el mensaje de la Iglesia Universal a la realidad de la patria latinoamericana.

El CELAM iba a producir el Documento de Medellín, guía importante para la acción social de la Iglesia y el Documento de Buga que terminaría con muchos mitos y asumiría una posición firme de compromiso para las universidades católicas del Continente. Era el tiempo en que los jóvenes educados dentro de un confesionalismo anticuado leíamos con entusiasmo y seguíamos con ansiedad a Obispos como Helder Camera, Méndez Arcéo y Leonidas Proaño, símbolos de una nueva Iglesia que surgía demandando un compromiso real con nuestros tiempos. Los cristianos seglares, superaban paulatinamente los mitos de una educación que los había formado para enfrentarse a liberales, comunistas y protestantes, buscaban el diálogo con sus anteriores enemigos, forjando nuevas posiciones que significaban enormes innovaciones tanto en la teología como en la política. La Democracia Cristiana en un extremo y las corrientes cristianas socialistas cuyo mejor símbolo fue el Sacerdote Camilo Torres, eran otros tantos esfuerzos por llegar a un compromiso que la nueva Iglesia demandaba.

En el caso ecuatoriano, esto se expresó en una serie de movimientos Cristianos como el Grupo de Reflexión, la Democracia Cristiana, los cristianos por el Socialismo, la Izquierda Cristiana y los grupos que emergieron desde la praxis política de la Universidad Católica, buscando el camino de un socialismo nacional en el que se reconozcan los valores cristianos de nuestro pueblo.

La universidad ecuatoriana, ya hemos anotado, vivía una etapa de transformación y violento enfrentamiento con el Estado. Los estudiantes universitarios, instrumentalizados o no por la oligarquía, habíamos sido elemento importante en el derrocamiento de la Junta Militar de Gobierno y, amparados por la Ley de Educación Superior de 1966, habíamos impulsado profundas transformaciones en el conjunto de la universidad ecuatoriana.

La figura de quien Malo afirma en una de sus obras ser el Máximo teórico universitario, el Doctor Manuel Agustín Aguirre, conducía un proceso de reforma en la Universidad Central, cuyas huellas no se han borrado de la universidad ecuatoriana. 
En la Universidad Católica, un grupo pequeño pero activo de estudiantes había comenzado a cuestionar radicalmente la estructura universitaria. Este sector estudiantil, formado en febrero de 1966 bajo el nombre de Frente Revolucionario Universitario, iba a crecer paulatinamente y a radicalizarse, dentro de una historia con grandes logros y grandes derrotas. Hacia Julio de 1966 se funda la Federación de Estudiantes Universitarios, se logra la representación estudiantil al Consejo Académico. Poco más tarde, la huelga de la Facultad de Derecho y la tenaz lucha de estudiantes cada vez más comprometidos, a la que empiezan a sumarse algunos profesores, logra la participación estudiantil en la elección de los Decanos y presiona para que la designación de Rector deje de ser un acto arbitrario de autoridades extrauniversitarias y tome en cuenta la opinión de estudiantes y profesores.

Cuando el proceso avanza y se profundiza, los dirigentes radicalizados de la Católica y del Colegio San Gabriel, ven abrirse las puertas de una facultad que hasta entonces había dictado sus materias en lenguas muertas, pero que se acoplaba a un nuevo tiempo hablando en castellano y buscando un nuevo compromiso con la historia, la Facultad de Filosofía San Gregario, dirigida por su Decano Hernán Malo González.

Escuela Superior de los Jesuitas, la Facultad de Filosofía Escolástica de San Gregario, reunía a un selecto grupo de maestros que conservando el rigor de los escolásticos alentaba la posibilidad de crear un nuevo pensamiento, fundamentalmente gracias al impulso de su carismático Decano.

En una ciudad como Quito, en la que todavía no existían escuelas universitarias en las que se pudiera estudiar ciencias sociales, la Facultad ejerció una extraña fascinación.

Estudiantes radicales de las universidades concurrieron a sus aulas. Dirigentes de la FEUE y del Frente de Izquierda de la Católica se mezclaron con estudiantes seminaristas, jesuitas y oblatos. Las rígidas tesis de las materias escolásticas se mezclaron con las proclamas de Daniel Cohn Bendit y las obras de Marcuse. Los tediosos libros acerca de la analogía del ser según Francisco Suárez su superpusieron con textos de Marx, el libreto de la ópera Hair, y el estudio de Margaret Rondall sobre los hippies. La Facultad más clerical de la Católica se había convertido en fermento incontrolable en el que amalgamaron las posiciones más diversas, en donde miembros de dos universidades hasta entonces totalmente enfrentadas, la Central y la Católica, se encontraron. 
Los golpes sufridos y también las locas aventuras emprendidas por sus estudiantes fueron expresión de este dinamismo y motivo de discusión, diálogo y crecimiento espiritual para sus miembros.

La muerte de René Pinto, el secuestro del Padre Camarata, la huelga del Seminario, las acciones solidarias con obreros, campesinos y estudiantes, se convirtieron en hitos de nuestra vida, en elementos de reflexión, tanto o más importantes que las obras de Hellín o de Santo Tomás.

Detrás de ese San Gregorio turbulento, pleno de crisis y por tanto de crecimiento, pleno de reflexión profunda y por tanto de compromiso vital, estaba la figura menuda, la inteligencia cultivada y el vitalismo hecho praxis del Profesor de Ética y Decano de la Facultad Hernán Malo González.

La descripción que hago de San Gregorio puede parecer idealista y alejada de la realidad. Se omiten en ella detalles propios de la vida, que vistos a la distancia, desaparecen por la dimensión de la obra realizada. Obviamente tuvimos discrepancias a veces violentas y puntos de vista encontrados.

Malo supo, sin embargo ayudarnos para buscar puntos de contacto y respetar las diferencias. Con él mismo como autoridad, más de una vez nos enfrentamos. (Recuerdo todavía su cara de sorpresa y angustia cuando un mediodía fui a la Facultad a comunicarle que un grupo integrado por la mayoría de estudiantes habíamos tomado bajo nuestra forzada protección al Padre Camarata. Su petición de que retrocediéramos y su solidaridad cuando conoció nuestras razones, pues sin compartir nuestras posiciones, supo respetarlas).

Hernán Malo, Decano de esta Facultad, fue visto por los dirigentes estudiantiles democráticos como el maestro que más nos comprendía. Cuando por primera vez los Jesuitas presentaron una terna a consideración de la Comunidad Universitaria para designar rector, esos grupos jóvenes, con la colaboración de algunos maestros y especialmente de una élite brillante de jesuitas que se reunía en torno a la revista Mensajero, impulsaron el nombre de Hernán para que se integre a esa terna y posteriormente condujeron una campaña que lo llevó a un resonante triunfo en la consulta.

El Decano del controvertido San Gregorio llegaba así al Rectorado de la Católica para inaugurar una nueva etapa de su historia. 


\section{EL PENSAMIENTO UNIVERSITARIO DE MALO: LA UNIVERSIDAD SEDE DE LA RAZÓN}

Malo explicita sus ideas acerca de la universidad en diversos ensayos y artículos, de los cuales parece ser central aquel que designó con el título de La Universidad, Sede de la Razón.

\section{El sentido del término razón:}

Para entender adecuadamente sus ideas, es preciso ante todo que clarifiquemos en forma esquemática qué entendía Malo por razón. Su concepción del término, alejada de cualquier frío racionalismo e imbuida fuertemente de elementos existencialistas y vitalistas, da al vocablo razón un sentido diverso al que comúnmente tiene.

Cuando en sus trabajos Malo quiere explicar el sentido del término razón, empieza por recurrir a conceptos platónicos, de Heráclito, su filósofo preferido, y a la obra de algunos filósofos y teólogos contemporáneos.

Dice Malo que en la concepción platónica de la verdad, es necesario precisar cuatro elementos:

a) La verdad es algo objetivo, más que subjetivo: es la realidad auténtica en cuanto tal.

b) La falsedad también es algo objetivo: existe un sector de esta realidad que, siendo objetivo, es falso.

c) El conocimiento falso entonces, más que falta de correspondencia entre el objeto conocido y el correlato intencional, es la aprehensión de lo falso.

d) De esto se desprende algo fundamental para entender la idea de Malo acerca de la razón y de su sede, la universidad: la búsqueda de la verdad en el hombre, más que un asunto gnoseológico, es una opción, un asunto moral.

Según la interpretación que hace Malo del pensamiento griego y convierte en eje de sus ideas, vivimos un mundo confuso, agitado por el devenir de cosas múltiples y opuestas, desligado de un Logos que es ante 
todo posibilidad de reflexión. La posibilidad de enfrentarlo pasa fundamentalmente por el ejercicio de la razón, razón que no se identifica simplemente con el raciocinio, sino que implica algo mucho más complejo: el pensamiento del ser humano como totalidad.

Analicemos un poco más lo que piensa Malo sobre la razón. Según él, en la Edad Moderna la razón entra en crisis porque se racionaliza. Al culminar el pensamiento escolástico, en la Edad Media, se había dado preeminencia al discurso lógico, con sus rígidos cánones silogísticos y su tendencia a descuidar los contenidos intelectivos de los términos, provocando la degeneración del nominalismo, antecedente inmediato del racionalismo.

La mente humana se concibe entonces casi totalmente despojada de elementos que no sean lógicos discursivos.

El pensamiento de Descartes, Liebnitz y Spinoza, hijo de alguna manera del nominalismo, llega a endiosar a la razón entendida como pensamiento rígido de tipo matemático, culminando sus empeños en la Ética Geométrica de Spinoza, que reduce el acto humano a un dato geométrico. La crisis de la razón agudizada con Kant y Hegel, encuentra para Malo una salida con la reacción antirracionalista representada por Schelling, el romanticismo alemán y el vitalismo francés y por la integración de la razón a la complejidad del pensamiento humano a través de la rica elaboración del existencialismo.

La concepción de la verdad en Platón y la idea de la crisis de la razón por el racionalismo tienen que ver con la concepción de Malo sobre el hombre, la filosofía y el mito. Otros, en su momento deberán estudiar detenidamente estos temas. Por ahora basta taparlos someramente con el fin de entender su concepto de razón y por tanto su idea de la universidad.

El hombre sufre un trauma básico al ubicarse en el mundo. Se siente un ser solitario, excepcional, adversario de todo lo que le rodea. Vive una feroz dialéctica en la que se oponen su fragilidad cotidiana, la pretensión de trascendencia y la superioridad de su mente.

Ante esto caben varias salidas: fugar del mundo, buscar la salida radical por el suicidio. Cabe también la reacción emocional de encerrarse en sí mismo dejando de lado todo interés por lo concreto.

Cabe sin embargo también otra salida: enfrentar el mundo con la razón. Buscar la verdad en un mundo en que tanto ella como su opuesto forman parte de lo objetivo. 
Buscar la verdad, ejercitar la razón, son pues para Malo opciones radicales que llevan a una idea de compromiso también radical con el mundo. Dice Malo que el encuentro con la verdad supone dar las espaldas al mundo y con toda el alma proyectarse de lo caduco hacia el mundo de las ideas.

La verdad no es una mera constatación de la correspondencia entre el objetivo formal y la imagen que nos hacemos de él en la mente, como pretenderían los racionalistas. La búsqueda de la verdad es ante todo un proceso con opciones dolorosas. Es muy difícil contemplar el sol. Puede conducirnos a la ceguera. Sin embargo, en la medida en que podemos hacerlo, llegamos a un nuevo momento de compromiso inevitable en la búsqueda de la verdad: el profeta trata de dialogar con su verdad, de llegar con ella a los demás.

Es entonces cuando los dogmáticos, los que quisieron rendir culto a las sombras, pueden victimar al comprometido con la razón.

De alguna manera entonces, el compromiso con la razón puede y tal vez trágicamente debe llevarnos al martirio.

El que cultiva la razón tiene un peligro. En palabras de Malo "el vulgo (ese vulgo que se arrincona en el más ilustrado de nosotros y que sale a flor de manifestaciones cuando nos comportamos como vulgares, lo cual acontece con frecuencia) tiene dos temores: a la crítica intelectual inquieta por la verdad y a la innovación".

Es entonces el "vulgo del intelecto", que odia a quienes buscan con inquietud la verdad y que teme la innovación, el principal enemigo de la razón.

Tomemos en cuenta entonces que, según Hernán, es esta "razón" que supone opción, que supone compromiso, que puede conducir al martirio, la que ha de regir a la universidad.

La razón, define Malo, "es la capacidad específica del ser humano para aproximarse al mundo, interpretarlo y así disponerse en forma específica humana a obrar. Su instrumento más apto es el raciocinio, su nota más profunda la reflexión".

La razón supone condiciones para ser ella misma. 
1. La razón es autónoma: esto no implica de ninguna manera que se convierta en una torre de marfil racionalista sin contacto con la realidad y el compromiso. Significa simplemente que la razón es la última instancia de sí misma, ningún conocimiento le está vedado. Su antítesis es el dogma entendido como imposición no razonada de premisas al pensamiento.

2. La razón está comprometida con la verdad. Este compromiso lleva a su cultor a desarrollar factores de calidad humana como el valor, la generosidad y el desinterés quijotesco. Cuando explica este concepto, Malo dice que el filósofo debe ser un caballero de la razón.

3. La razón es crítica: vuelve sobre sus conocimientos, los critica permanentemente. Por tanto la razón permanece en un permanente cuestionarse a sí misma.

4. La razón es hija del diálogo. Nace en el diálogo consigo mismo y con otras razones posibles. Dialogar con el mundo objetivo supone interpretación y búsqueda de una acción humana. Diálogo entre la teoría y la experiencia.

5. Finalmente la razón es práctica, ninguna razón puede desligarse de lo práctico. El hombre, fiel al dictado y reglas de juego de la razón, debe gobernar el mundo, perfeccionarlo y perfeccionarse a sí mismo.

No cabe una razón teórica separada de la praxis. Toda expresión de la razón, aun la más abstracta, supone una praxis.

\section{La Universidad, sede de la razón}

Hemos expuesto el sentido de la razón para Malo, para entonces entender su idea de la universidad.

Malo fue un maestro que sentía hondamente a la universidad ecuatoriana y la defendía. En este sentido fue el primer rector de la Católica capaz de ponerse por encima de viejas rencillas nacidas de la oposición entre un laicismo delirante y una clerecía anticuada.

Hernán pensó en la Universidad, en su conjunto y escribió siempre para la Universidad ecuatoriana no sólo para la Católica.

Cuando introduce su I Tomo de pensamiento universitario, Malo nos habla de la acusación que se hace en contra de la Universidad, argumentando que es una institución perversa. 
Aclara allí que el papel de la universidad como conciencia crítica de la sociedad lleva a que los grupos económicos y políticos la ataquen y pretendan atribuirle una condición perversa.

La universidad es vista como mala siempre que ejerce su crítica, siempre que los estudiantes, "los jóvenes universitarios con sus altos revolucionarios y sus bajos acomodaticios se ponen en una línea de transformación".

No toman en cuenta los enemigos de la universidad que el florecimiento o la crisis de la institución universitaria no pueden ser analizados sino dentro del marco de la crisis de la sociedad global.

Dice Malo que el mal estudiante universitario es fruto de una educación anterior deficiente, que la masificación o democratización no es un capricho, sino el fruto del deseo de superación de las clases marginadas a las que el sistema no da otras posibilidades de desarrollo.

Cito textualmente:

La inmediatez inquietud del estudiante universitario no fueron inventados por Marx ni por la perfidia de los tercermundistas, son frutos entrañables de la vida.

La universidad, cumpliendo su papel crítico, puede por momentos ser violentada, pero quienes critican este defecto de la universidad olvidan dos elementos:

El primero, que la violencia de los estudiantes comparativamente es poca comparada a las violencias injustificadas, represivas, institucionalizadas que todos los días se cometen en nuestra patria.

Por otra parte, siempre se atribuye a la universidad presente un grado de violencia mayor a la anterior, lo cual es históricamente falso.

Lo que ocurre es que en el pensamiento de los defensores de lo establecido, una historia depurada, de sus elementos vitales, y desfigurada, sirve de argumento contra la innovación. La universidad de antes es vista entonces siempre como la mejor, los innovadores de otros tiempos son utilizados para combatir toda innovación presente, si limpiamos sus biografías de sus aspectos más cuestionados y cuestionadores; cuando el pensador muere puede incluso ser retomado como la negación de lo que fue, para frustrar con su caricatura las ansias de transformación de las nuevas generaciones. 
En fin, volvemos a la Universidad perversa. Universidad perversa pintada por los enemigos de la innovación y de la historia. Universidad perversa que es caricatura de nuestra universidad inventada por los enemigos de la razón.

Frente al mito de universidad perversa, Malo nos llama a emprender una gran campaña nacional de reivindicación y dignificación de la universidad ecuatoriana ante la opinión pública y nuestras propias conciencias.

Esto no supone que la Universidad no se auto-critique. Lo veremos más adelante, lo autocrítico es fundamental, pero no puede ejercerse deslealmente, sin a la vez emprender esta gran cruzada de defensa de la Sede de la Razón.

Digamos finalmente qué implica la definición de la Universidad como Sede de la Razón.

La Universidad es una necesidad primordial de la comunidad humana. En cualquier sitio del mundo en donde algunos hombres cultivados se reúnen para indagar y dialogar sobre el mundo, si ese diálogo se sistematiza y se institucionaliza, tenemos una universidad.

Recordemos los elementos de su definición de razón, acercarse al mundo, interpretarlo, llegar a un obrar humano. Para Malo en definitiva cuando se sistematiza y se afina lo más esencial del hombre: su capacidad de razón, tenemos ya a la Universidad.

Veremos qué consecuencias trae este hecho, de que la Universidad sea la Sede de la Razón:

1. $\quad$ En primer lugar la Universidad es la Sede de la autonomía de la Razón. Para poder ser tal, la Universidad debe ser profundamente pluralista. Debe garantizar la libertad a todas las posiciones en su seno. La autonomía así entendida tiene dos enemigos. El uno es el dogmatismo interno de cualquier orientación política o religiosa. El dogma interno lleva a la imposición irracional o subracional de los principios, lleva a la negación de la diferencia como elemento fundamental de la posibilidad dialéctica.

El otro enemigo es el externo, la posibilidad de manipulación por parte de grupos con intereses económicos, políticos o religiosos. Tanto los que defienden el sistema como quienes lo atacan sienten la tentación de manipular a la Universidad conforme a sus fines. La Universidad, Sede de la autonomía de la Razón, ha de defenderse de esos riesgos. 
2. La Universidad en tanto que Sede de la Razón se compromete con la verdad. El compromiso con la verdad atraviesa a la Universidad en todos los sentidos y la lleva siempre al heroísmo. Este heroísmo puede concretarse en muy diversas formas; ya sea en el constante y gris esfuerzo de todos los docentes y estudiantes por esclarecer la verdad en el diálogo con la razón, ya viviendo momentos en que individual o colectivamente los universitarios se ven en la circunstancia de entregar aun la vida, en defensa de lo que creen cierto.

3. La Universidad, Sede de la Razón, está definitivamente comprometida con lo crítico. Esa crítica tiene ante todo que aplicarse a sí misma. Más allá de los disparatados mitos creados por quienes definen a la Universidad como institución perversa, es verdad que la Universidad tiene y tendrá siempre enormes defectos sobre los que deberá ejercer su función crítica.

Por otra parte, la Universidad, Sede de una Razón que es entendida no como frío raciocinio sino como opción y compromiso, debe ejercer un acto eminentemente político: criticar a la sociedad radicalmente y encontrar después de su reflexión una nueva posibilidad de acción más humana.

4. La razón es ante todo diálogo y la Universidad, Sede de la Razón, es la institución en la que el diálogo llega a su mejor expresión. La exaltación emotiva está fuera de su ámbito. El diálogo es consecuencia lógica de los elementos antes anotados.

5. Finalmente, la razón conduce a la Universidad a un compromiso con lo práctico. En esto, la Universidad ha de ser cuidadosa, su compromiso con la realidad no puede traducirse en un mero practicismo inmediatista. Buscando el compromiso con lo concreto, ha de preocuparse también por lo mediato.

El compromiso con la práctica nos lleva a la Universidad institución política. En cita de Malo:

La Universidad no política es a la postre una Universidad cercenada y carente de sentido para el hombre. El academicismo y el religionismo se rasgan irracionalmente las vestiduras atacando a la política en la Universidad, sin darse cuenta que ellos mismos son eminentemente políticos. 


\section{Notas finales.}

Apretadamente hemos resumido lo más importante del pensamiento universitario de Hernán Malo González.

Terminemos con unas breves reflexiones acerca de su acción como dirigente universitario.

Llevando adelante sus ideas, el Rector de la Católica rompió una tradición de sectarismo y aislamiento. Ya como Decano de San Gregario a propósito de la muerte de uno de sus estudiantes, René Pinto, conoció los predios de la Central, según me comentó más tarde, embargado de temores nacidos de su educación dentro de la lucha liberal-confesional.

Superando enormes prejuicios, empezó a asistir regularmente a las reuniones con rectores y dirigentes estudiantiles. El rector de un colegio mayor se iba incorporando al conjunto de rectores de las universidades ecuatorianas, en la medida en que su colegio se transformaba en universidad.

En pocos años sucedió lo increíble. El Rector de la Católica era tratado con cariño y respeto por los universitarios de las más diversas corrientes.

Dirigentes de la FEUE, artistas, escritores, dirigentes de izquierda, lo mismo que dirigentes de la propia universidad le trataban con confianza y cariño, simplemente por su nombre: Hernán.

Cuando fui presidente de la Federación de Estudiantes me acostumbré a que me preguntaran personas de las más diversas universidades y posiciones ideológicas: "¿qué es de Hernán?", „¿cómo le va a Hernán?". Para quienes trabajamos con él, ya avanzado el proceso, fue frecuente verlo salir a almorzar con el Rector de la Central, con quien hizo grande amistad.

Nunca habría sido pensable que esto ocurra con algunos de los rectores que le precedieron. Hernán Malo fue, con Pérez Guerrero, Manuel Agustín Aguirre y Carlos Cueva Tamariz, una de las grandes figuras de la Universidad ecuatoriana en su conjunto, la primera figura de esa magnitud salida del sector cristiano. 
Su compromiso con la Sede de la Razón le llevó a ingeniar métodos que permitieran el acceso a la Universidad a estudiantes de bajos recursos, a través de la pensión diferencial. En su período se crearon y consolidaron las asociaciones de profesores y trabajadores, la FEUCE vivió una etapa plena de creación y compromiso.

La vivencia práctica de la Universidad le llevó a plantear la ecuatorianización entendida como compromiso de la Universidad con nuestro país, con sus clases menos favorecidas, buscando vías realmente ecuatorianas para enfrentar sus problemas.

La Católica adquirió una dimensión nacional. Las Sedes de Cuenca e Ibarra significaron un esfuerzo por descentralizar la institución y hacerla representativa de la nación.

La obra de Malo como rector merece todo un trabajo aparte para entender cómo llevó a la práctica sus teorías universitarias. Tengo el deseo de desarrollar ese estudio próximamente, pero esta noche ya os he cansado demasiado con tantas y tantas palabras, que apenas logran esbozar toscamente el pensamiento de uno de nuestros mayores maestros ecuatorianos.

Terminaré diciendo que la vida llevó a Hernán Malo avivir lo que él creía acerca del que cultiva la razón y la verdad. Mentes chatas y mediocres, el vulgo que teme la innovación y odia a quien usa la razón, un vulgo que a veces está también en las altas esferas y por desgracia ejerce funciones de poder, determinó su salida del rectorado.

Profesores, estudiantes y trabajadores protestaron indignados. Era posible ir incluso a una ruptura en que aquellos que representaban la renovación de la Universidad y el cristianismo, demostraran a determinados burócratas extraños a la Universidad que ya no eran necesarios.

Malo fue leal a la Iglesia, a la jerarquía, a la Compañía de Jesús. Fue quien detuvo la presión de sus seguidores y admitió que la Universidad fuera rescatada por las fuerzas conservadoras.

Tuvo la ilusión de conservar su cátedra. Los chatos se lo impidieron. 
Volviendo al principio, fue esta Sede de la Universidad Católica la que lo mantuvo al frente de la docencia y, cosa insólita en otros casos, fue la Universidad Central la que acogió al Padre Hernán y le brindó su mano.

Hernán Malo emprendió nuevas empresas. Se dedicó a cultivar y difundir la cultura ecuatoriana desde la Corporación Editora Nacional.

Se dedicó también a escribir sus ideas universitarias, a desarrollarlas para iluminar una universidad que vendrá.

Así siguió su camino en medio de una soledad que no podíamos llenar los pocos amigos que fuimos fieles a la praxis política vivida en la Universidad y lo rodeamos en sus nuevos intentos.

Una soledad acrecentada por los rostros agrios y los desplantes de empleadillos de mínima estatura humana que le volvían la cara después de haber perdido el poder.

Hernán Malo siguió un difícil camino, un sendo angustiado en busca de la verdad, luchando al mismo tiempo contra los molinos de viento de la sociedad injusta y con las ansias internas por acercarse más a esa contemplación de la verdad que duele y lleva a la profecía.

Hernán Malo fue hasta el fin de sus días un cultor de esa razón vitalista que según sus ideas debía regir a la universidad y un defensor ferviente de la universidad ecuatoriana y sus posibilidades de desarrollo.

Hernán Malo fue finalmente algo que ninguno de sus enemigos le pudo impedir. Algo por lo que sus discípulos y amigos lo admiramos siempre: Hernán Malo fue un caballero de la razón. 
